\title{
Changes in Bone Mineral Density through 96 Weeks in Antiretroviral-Naïve HIV-1 Infected Patients Receiving Abacavir/Lamivudine and Raltegravir in the SHIELD Trial
}

\author{
Linda Battalora ${ }^{1,2}$, Amy Thomas ${ }^{2}$, Brian Wine ${ }^{3}$, Belinda Ha ${ }^{3}$, Benjamin Young ${ }^{2,4 *}$ \\ ${ }^{1}$ Colorado School of Mines, Golden, USA \\ ${ }^{2}$ APEX Research/Family Medicine, Denver, USA \\ ${ }^{3}$ GlaxoSmithKline, Research Triangle Park, USA \\ ${ }^{4}$ International Association of Providers of AIDS Care, Washington, USA \\ Email: "byoung@iapac.org
}

Received 7 October 2013; revised 7 November 2013; accepted 14 November 2013

Copyright $@ 2014$ by authors and Scientific Research Publishing Inc.

This work is licensed under the Creative Commons Attribution International License (CC BY).

http://creativecommons.org/licenses/by/4.0/

(c) (i) Open Access

\section{Abstract}

Decreased bone mineral density (BMD) and osteoporotic fractures are areas of increasing concern among HIV-infected persons. Particular concern is the rapid decline in BMD after initiation of antiretroviral treatment (ART). This report describes DEXA-assessed changes in BMD and body fat in a study of fifteen antiretroviral-naïve adults initiating abacavir/lamivudine and raltegravir for 96 weeks. Median percent changes from baseline at weeks 48 and 96 in BMD were $0.29 \%$ and $-0.11 \%$ (spine); $-\mathbf{1 . 2 5 \%}$ and $-\mathbf{1 . 7 5} \%$ (left hip). Median percent changes from baseline in fat from baseline were $-0.82 \%$ and $-3.04 \%$ (trunk); $2.12 \%$ and $2.01 \%$ (limb). In this pilot study, ABC/3TC + RAL treatment had limited impact on BMD and body fat.

\section{Keywords}

Bonedensity; Abacavir; HIV; Integrase; Lamivudine; Raltegravir

${ }^{*}$ Corresponding author.

How to cite this paper: Battalora, L., Thomas, A., Wine, B., Ha, B. and Young, B. (2014) Changes in Bone Mineral Density through 96 Weeks in Antiretroviral-Naïve HIV-1 Infected Patients Receiving Abacavir/Lamivudine and Raltegravir in the SHIELD Trial. World Journal of AIDS, 4, 38-44. http://dx.doi.org/10.4236/wja.2014.41005 


\section{Introduction}

There is a growing concern about the risks of decreased bone mineral density [1] and osteoporotic fractures [2] [3] among HIV-infected persons. Among multiple risk factors, some antiretroviral medications have been implicated in reduction in bone mineral density (BMD) [4] [5] or bone fracture [6] [7]. Of note, a rapid decline in BMD has been observed after the initiation of antiretroviral treatments [8].

\section{Review}

Previously in this journal, we reported the 48- and 96-week results of an open-label, prospective, pilot trial of abacavir/lamivudine (ABC/3TC) and the integrase strand transfer inhibitor (INSTI) raltegravir (RAL) in HIV-1infected, antiretroviral (ART)-naïve adults (COL111429, the SHIELD Study) [9] [10]. In the SHIELD study, ABC/3TC + RAL demonstrated durable virologic suppression through week 96 in those patients who remained on treatment and was generally well tolerated with little toxicity reported. RAL is a preferred antiretroviral agent in current US Department of Health and Human Services guidelines for the initial treatment of HIV-1 infected adults and ABC + 3TC + RAL has been added to the list of alternate regimens [4]. While a growing body of literature has reported on the impact of nucleoside reverse transcriptase inhibitors, including impact of $\mathrm{ABC} / 3 \mathrm{TC}$ and TDF/FTC on BMD, there is a paucity of data on the effects of raltegravir on BMD and none with the ABC/ 3TC + RAL combination. This publication reports the changes in bone mineral density in a subset of SHIELD subjects.

SHIELD included HIV-1-infected individuals who were $\geq 18$ years of age, ART-naïve, HLA-B * 5701-negative, and had screening HIV-1 RNA > 1000 copies/mL within 21 days prior to study enrollment. Inclusion and exclusion criteria are detailed in the 48-week report [9] and all patients provided written informed consent. Enrolled patients were given coformulated ABC/3TC 600 mg/300 mg (Epzicom ${ }^{\circledR}$, GlaxoSmithKline, Research Triangle Park, NC) dosed 1 tablet once daily and RAL 400 mg (Isentress ${ }^{\circledR}$, Merck \& Co., Inc., Whitehouse Station, NJ) dosed 1 tablet twice daily. Subjects from a single site underwent BMD and body composition measurement by DEXA (GE Lunar Podigy 1RDF + 15700) at baseline and weeks 48 and 96. All laboratory tests were performed at a central laboratory by Quest Diagnostics (Van Nuys, California, USA).

The majority of the 15 patients enrolled in this sub-study were white (87\%) and male (93\%). Their mean age (SD) was 39.5 (9.8) years and mean weight was 85.5 (14.9) kg. Mean height was 180.5 (8.9) cm and mean BMI was 26.4 (5.6). The baseline demographics and patient characteristics of this group are shown in Table 1 and is similar to the entire SHIELD cohort, as previously reported [9].

Fourteen of 15 subjects completed week 96 of the study. At week 96, HIV-1 RNA was <50 copies/mL in 93\% (14/15) of patients using an MD = F analysis. One patient experienced confirmed virologic failure and discontinued from the study at week 48. This individual was later found to have been infected with virus resistant to four drug classes and has been reported in detail elsewhere [11]. As was seen in the entire SHIELD cohort, immunologic results were robust, with a median change from baseline in CD4 cell count of +207 cells $/ \mathrm{mm}^{3}$ at week $48(n=15)$ and +291 cells $/ \mathrm{mm}^{3}$ at week $96(n=14)$.

In this study, limited changes in the median bone mineral density at the spine (total) and left hip, and trunk and limb total body fat were observed (Figure 1, Table 2). Median percent change from baseline in spine BMD increased by $0.29 \%$ at week 48 and decreased by $-0.11 \%$ at week 96 . Median percent change from baseline in left hip BMD decreased by $-1.25 \%$ at week 48 and decreased by $-1.75 \%$ at week 96 . Median changes from baseline in T-score at 48 and 96 weeks were 0.0 and 0.0 for the spine and -0.10 and -0.15 for the left hip. Trunk fat median percent changes from baseline were $-0.82 \%$ at week 48 and $-3.04 \%$ at week 96 . Limb total fat median percent changes from baseline were $2.12 \%$ at week 48 and $2.01 \%$ at week 96 .

One fracture reported among the fifteen subjects. This subject had fractured ribs, associated with trauma unrelated to study medications.

A number of prospective clinical trials have evaluated changes in bone mineral density among individuals initiating antiretroviral therapy. Greater decreases in spine and hip BMD through 96 weeks in participants randomized to receive TDF-FTC compared to ABC-3TC in the A5224s study (substudy of ACTG A5202) [4] in which 269 HIV-infected, treatment naïve participants were randomized to receive ABC/3TC or TDF-FTC with efavirenz (EFV) or atazanavir plus ritonavir (ATV/r). A greater bone loss predicted by lower bone formation and lower fat mass was reported in patients receiving TDF-FTC than those receiving ABC-3TC through 96 weeks in the STEAL study [12]. In another study, switching from zidovudine/lamivudine (ZDV/3TC) to TDF/ 
Table 1. Baseline patient demographics, characteristics, and medical history.

\begin{tabular}{|c|c|}
\hline & $N=15$ \\
\hline Median age, years (range) & $41.0(25-55)$ \\
\hline \multicolumn{2}{|l|}{ Sex, n (\%) } \\
\hline Female & $1(7 \%)$ \\
\hline Male & $14(93 \%)$ \\
\hline \multicolumn{2}{|l|}{ Race, n (\%) } \\
\hline African American/African Heritage & $2(13 \%)$ \\
\hline White/Caucasian/European Heritage & $13(87 \%)$ \\
\hline \multicolumn{2}{|l|}{ Ethnicity, n (\%) } \\
\hline Hispanic or Latino & $1(7 \%)$ \\
\hline Not Hispanic or Latino & $14(93 \%)$ \\
\hline Median plasma HIV-1 RNA, $\log _{10}$ copies/mL (IQR) & $4.857(4.243-5.124)$ \\
\hline$<100,000$ copies/mL, n (\%) & $10(67 \%)$ \\
\hline$\geq 100,000$ copies $/ \mathrm{mL}, \mathrm{n}(\%)$ & $5(33 \%)$ \\
\hline Median CD4 cell count, cells $/ \mathrm{mm}^{3}$ (IQR) & $322(264-413)$ \\
\hline$<50$ cells $/ \mathrm{mm}^{3}, \mathrm{n}(\%)$ & $1(7 \%)$ \\
\hline$\geq 200$ cells $/ \mathrm{mm}^{3}, \mathrm{n}(\%)$ & $14(93 \%)$ \\
\hline \multicolumn{2}{|l|}{ Adult CDC classifications for HIV infection, n (\%) } \\
\hline Category A & $13(87 \%)$ \\
\hline Category B & $2(13 \%)$ \\
\hline Median BMI* (range) & $25.9(19-36)$ \\
\hline \multicolumn{2}{|l|}{ Weight status based on BMI } \\
\hline Normal, $18.5 \leq \mathrm{BMI}<25$, n (\%) & $7(47 \%)$ \\
\hline Overweight, $25 \leq \mathrm{BMI}<30$, n (\%) & $4(27 \%)$ \\
\hline Obese, $\geq 30, \mathrm{n}(\%)$ & $4(27 \%)$ \\
\hline \multicolumn{2}{|l|}{ Tobacco Use, $\mathrm{n}(\%)^{* *}$} \\
\hline Current smoker & $4(27 \%)$ \\
\hline Current smoker & $2(13 \%)$ \\
\hline Never smoked & $9(60 \%)$ \\
\hline \multicolumn{2}{|l|}{ Diabetes Type II, n (\%) } \\
\hline Current condition & $1(7 \%)$ \\
\hline Past history & $1(7 \%)$ \\
\hline No history or condition & $13(87 \%)$ \\
\hline \multicolumn{2}{|l|}{ Family history of heart attack/stroke, n (\%) } \\
\hline No & $11(73 \%)$ \\
\hline Yes & $4(27 \%)$ \\
\hline Median Weight (kg) (range) & $80.9(59-111)$ \\
\hline Median Height (cm) (range) & $178.0(173-206)$ \\
\hline \multicolumn{2}{|l|}{ Exercise History } \\
\hline Often or very often & $8(53 \%)$ \\
\hline Sometimes & $5(33 \%)$ \\
\hline Seldom or never & $2(13 \%)$ \\
\hline Spine Total BMD $\left(\mathrm{g} / \mathrm{cm}^{2}\right)$ & \\
\hline
\end{tabular}




\section{Continued}

\begin{tabular}{cc}
\hline Median (IQR) & $1.29(1.17-1.39)$ \\
Spine Total T-score & \\
Median (IQR) & $0.60(-0.40-1.50)$ \\
Spine Total Z-score & \\
Median (IQR) & $0.30(-0.50-1.00)$ \\
Left Hip BMD (g/cm $\left.{ }^{2}\right)$ & $1.09(0.99-1.16)$ \\
Median (IQR) & \\
Left Hip T-score & $0.30(-0.70-0.40)$ \\
Median (IQR) & \\
Left Hip Z-score & $-0.10(-0.60-0.70)$ \\
Median (IQR) & $1.11(0.99-1.17)$ \\
Right Hip BMD (g/cm $\left.{ }^{2}\right)$ & \\
Median (IQR) & \\
Right Hip T-score & $0.30(-0.70-0.50)$ \\
Median (IQR) & \\
Right Hip Z-score & $-0.10(-0.70-0.50)$ \\
Median (IQR) &
\end{tabular}

Abbreviations: BMI, body mass index; IQR, interquartile range; SD, standard deviation; ${ }^{*} \mathrm{BMI}=$ weight $(\mathrm{kg}) /$ height $(\mathrm{m})^{2} ;{ }^{* *}$ Percentages do not add to $100 \%$ due to rounding.

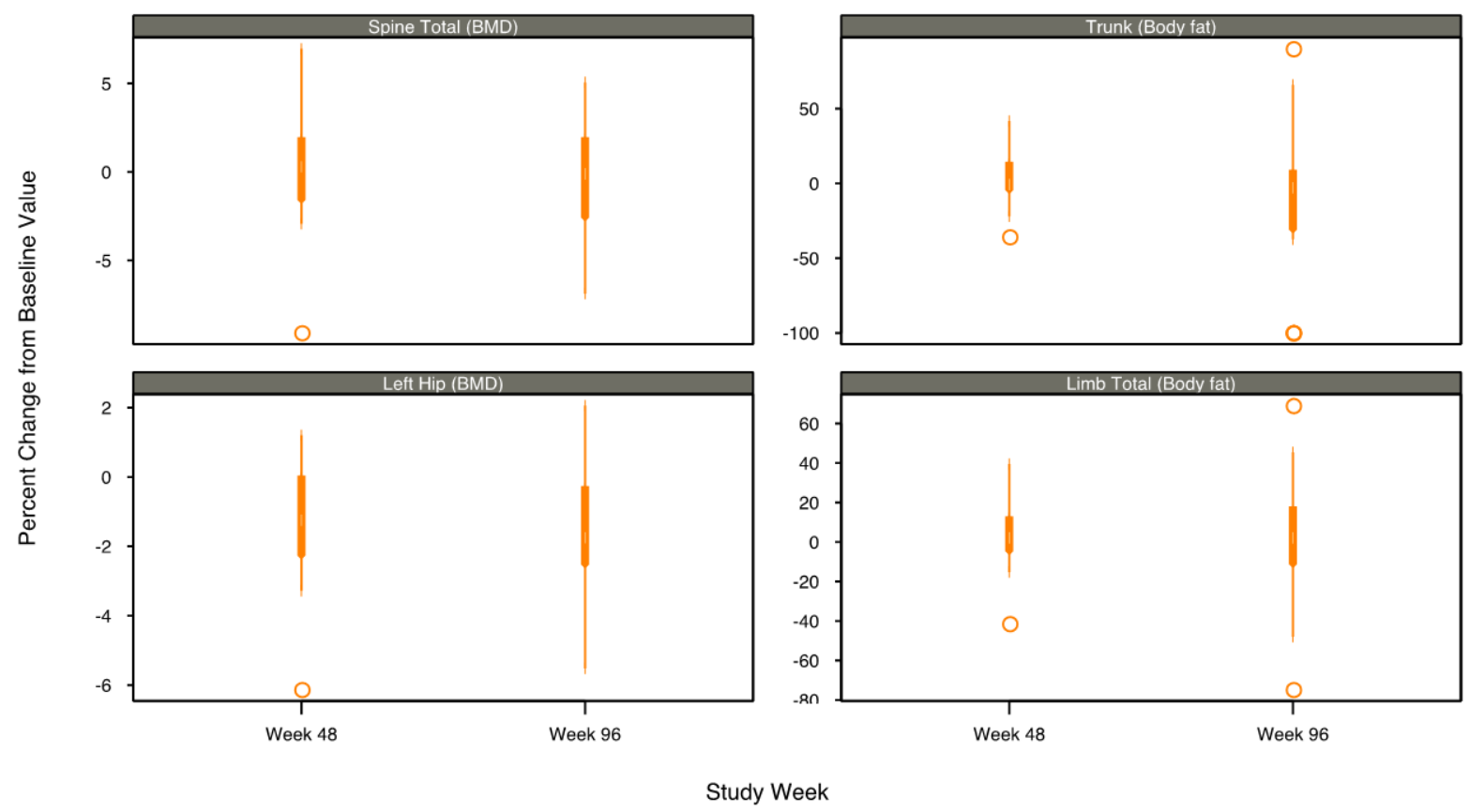

Figure 1. Box plots of DEXA measurements by body region and visit-median percent change from baseline.

FTC regimen resulted in increased bone turnover markers and decreased BMD through 48 weeks compared to ABC-3TC switch [13]. In the ASSERT study, ART-naïve, immunodeficient, young (mean age 37 years old), ethnically diverse participants treated with TDF-FTC compared with ABC-3TC experienced greater increases in bone turnover and decreases in BMD at 48 weeks [14].

Other studies report changes in BMD of participants randomized to receive RALin antiretroviral combinations. In the PROGRESS study, ART-naive participants randomized to receive lopinavir/ritonavir (LPV/r) plus 
Table 2. Changes in BMD and total body fat by body region over time.

\begin{tabular}{|c|c|c|c|c|}
\hline \multicolumn{5}{|c|}{ Median Percent Changes in BMD and Total Body Fat by Body Region Over Time ${ }^{1}$} \\
\hline Weeks & $\begin{array}{l}\text { Percent Change in } \\
\text { Spine Total BMD } \\
(\%) \text { Median (IQR) }\end{array}$ & $\begin{array}{l}\text { Percent Change in } \\
\text { Left Hip BMD (\%) } \\
\text { Median (IQR) }\end{array}$ & $\begin{array}{l}\text { Percent Change in Trunk Body } \\
\text { Fat (\%) Median (IQR) }\end{array}$ & $\begin{array}{l}\text { Percent Change in Limb } \\
\text { Total Body Fat (\%) } \\
\text { Median (IQR) }\end{array}$ \\
\hline $0-48$ & $0.29(-1.8-2.1)$ & $-1.25(-2.5-0.2)$ & $-0.82(-5.8-15.2)$ & $2.12(-4.8-15.8)$ \\
\hline $0-96$ & $-0.11(-2.6-2.1)$ & $-1.75(-2.5-0.2)$ & $-3.04(-37.3-10.9)$ & $2.01(-13.9-21.1)$ \\
\hline \multicolumn{5}{|c|}{$\underline{\text { Median Changes in BMD (grams } / \mathrm{cm}^{2} \text { ) and Total Body Fat (grams) by Body Region Over Time }{ }^{1}}$} \\
\hline Time & $\begin{array}{l}\text { Spine Total BMD } \\
\text { Median (IQR) }\end{array}$ & $\begin{array}{l}\text { Left Hip BMD } \\
\text { Median (IQR) }\end{array}$ & $\begin{array}{c}\text { Trunk Body Fat Trunk } \\
\text { Body Fat }\end{array}$ & $\begin{array}{l}\text { Limb Total Body Fat } \\
\text { Median (IQR) }\end{array}$ \\
\hline Baseline/Day 1 & $1.29(1.17-1.39)$ & $1.09(0.99-1.16)$ & $15421.00(10556.0$ - 20180.0) & $8413.00(6643.0-12184.0)$ \\
\hline Week 48 & $1.31(1.15-1.36)$ & $1.10(1.00-1.15)$ & $17214.00(8288.00$ - 23285.0) & $8591.00(6241.0$ - 13819.0) \\
\hline Week 96 & $1.31(1.17-1.34)$ & $1.09(0.98-1.17)$ & 12413.50 (6619.0 - 19996..0) & $8477.00(6154.0$ - 9098.0) \\
\hline
\end{tabular}

${ }^{1}$ At Baseline and Week 48, $n=15$; at week 96, $n=14$.

TDF/FTC demonstrated at 96 weeks a $-2.48 \%$ mean percent decrease in BMD from baseline $(\mathrm{p}<0.001)$ compared with a $0.68 \%$ decrease in BMD in ART-naive participants randomized to receive LPV/r plus RAL [15]. Increases in peripheral fat, but not trunk fat were observed in the LPV/r plus RAL patients. In the KITE study, virologically suppressed HIV-infected patients who were switched from standard highly active ART to a nucleoside reverse transcriptase inhibitor (NRTI) sparing combination of LPV/r and RAL showed no differences between the regimens in BMD, total body fat composition, creatinine clearance or CD4 Tcell counts at week 48 [16].

\section{Conclusions}

The conclusions of this study are limited by the non-comparative nature and small sample size inherent to pilot studies. Subjects in this analysis were largely healthy men with normal baseline BMI, perhaps minimizing their non-HIV risk factors for loss of BMD notwithstanding these limitations. This study provides an exploratory look at changes in bone mineral density in antiretroviral-naïve HIV-1 infected patients taking ABC/3TC + RAL .

In this pilot study of therapy naïve individuals, ABC/3TC + RAL treatment appears to have limited impact on BMD and body fat through 96 weeks. ABC/3TC + RAL demonstrated durable virologic suppression and was generally well tolerated in those patients who remained on treatment through week 96 . The results of this study, though limited by a small sample size and single-arm design, suggest the effectiveness and safety of ABC/3TC with an INSTI. This combination should be tested in a larger, randomized trial.

\section{Acknowledgements}

The SHIELD Study investigators were: Edwin Dejesus, Orlando, Florida; Trevor Hawkins, Santa Fe, New Mexico; Thanes Vanig, Phoenix, Arizona; Benjamin Young, Denver, Colorado.

This investigator-initiated study was funded by GlaxoSmithKline. We gratefully acknowledge the patients who participated in this study. We thank the study coordinators along with the teams from GlaxoSmithKline (Evit Blackmon, Kathleen Dudas, Christina Frederick-Fuerlein, Deanna Merrill, PharmD, IlisseMinto, Keith Pappa, PharmD, Sue Pippin, Lisa Ross, Shannon Labelle, and Brian Wine) and Medistaf (Vicky Fantry and Bruce Uveges).

\section{Previous Publications}

This study was presented in part at the 11th International Workshop on Adverse Drug Reactions and Co-morbidities in HIV, 26-28 October, 2009, Philadelphia, PA; the 12th European AIDS Conference, 11-14 November 2009, Cologne, Germany; the XVIII International AIDS Conference, 18-23 July 2010, Vienna, Austria, and the 6th IAS Conference on HIV Pathogenesis, Treatment and Prevention, 17-20 July 2011, Rome, Italy. 


\section{Disclosures}

Benjamin Young has received consulting fees from Bristol-Myers Squibb Company, Cerner Corporation, Gilead Sciences, GlaxoSmithKline, Merck \& Co., Tibotec, and ViiV Healthcare. He has served on speakers' bureaus for Merck \& Co., and ViiV Healthcare. In addition, he has received research funding from Bristol-Myers Squibb Company, Cerner Corporation, Gilead Sciences, GlaxoSmithKline, and Merck \& Co.

Belinda Ha is an employee of GlaxoSmithKline.

Brian Wine is a contractor for GlaxoSmithKline.

Linda Battalora has no disclosures.

Amy Thomas has no disclosures.

\section{References}

[1] Brown, T.T. and Qaqish, R.B. (2006) Antiretroviral Therapy and the Prevalence of Osteopenia and Osteoporosis: A Meta-Analytic Review. AIDS, 20, 2165-2174. http://dx.doi.org/10.1097/QAD.0b013e32801022eb

[2] Triant, V.A., Brown, T.T., Lee, H. and Grinspoon, S.K. (2008) Fracture Prevalence among Human Immunodeficiency Virus (HIV)-Infected versus Non-HIV-Infected Patients in a Large U.S. Healthcare System. The Journal of Clinical Endocrinology and Metabolism, 93, 3499-3504. http://dx.doi.org/10.1210/jc.2008-0828

[3] Young, B., Dao, C., Buchacz, K., Baker, R. and Brooks, J.T. (2011) Higher and Increasing Rates of Fracture among HIV-Infected Persons in the HIV Outpatient Study (HOPS) Compared to the General U.S. Population, 1994-2008. Clinical Infectious Diseases, 52, 1061-1068. http://dx.doi.org/10.1093/cid/ciq242

[4] McComsey, G.A., Kitch, D., Daar, E.S., et al. (2011) Bone Mineral Density and Fractures in Antiretroviral-Naive Persons Randomized to Receive Abacavir-Lamivudine or Tenofovirdisoproxilfumarate-Emtricitabine along with Efavirenz or Atazanavir-Ritonavir: Aids Clinical Trials Group A5224s: A Substudy of ACTG A5202. The Journal of Infectious Diseases, 203, 1791-1801. http://dx.doi.org/10.1093/infdis/jir188

[5] Yin, M.T., Zhang, C.A., McMahon, D.J., et al. (2012) Higher Rates of Bone Loss in Postmenopausal HIV-Infected Women: A Longitudinal Study. The Journal of Clinical Endocrinology and Metabolism, 97, 554-562. http://dx.doi.org/10.1210/jc.2011-2197

[6] Yin, M.T., Kendall, M.A., Wu, X., et al. (2012) Fractures after Antiretroviral Initiation. AIDS, 26, 2175-2184. http://dx.doi.org/10.1097/QAD.0b013e328359a8ca

[7] Bedimo, R., Maalouf, N.M., Zhang, S., Drechsler, H. and Tebas, P. (2012) Osteoporotic Fracture Risk Associated with Cumulative Exposure to Tenofovir and Other Antiretroviral Agents. AIDS, 26, 825-831. http://dx.doi.org/10.1097/QAD.0b013e32835192ae

[8] Brown, T.T., McComsey, G.A., King, M.S., Qaqish, R.B., Bernstein, B.M. and da Silva, B.A. (2009) Loss of Bone Mineral Density after Antiretroviral Therapy Initiation, Independent of Antiretroviral Regimen. Journal of Acquired Immune Deficiency Syndromes, 51, 554-561. http://dx.doi.org/10.1097/QAI.0b013e3181adce44

[9] Young, B., Vanig, T., DeJesus, E., et al. (2010) A Pilot study of Abacavir/Lamivudine and Raltegravir in Antiretroviral-naïve HIV-1-Infected Patients: 48-Week Results of the SHIELD Trial. HIV Clinical Trials, 11, 260-269. http://dx.doi.org/10.1310/hct1105-260

[10] Young, B., Vanig, T., DeJesus, E., Hawkins, T., St. Clair, M., Stancil, B., Ha, B. and the SHIELD Study Team (2011) 96-Week Results of a Pilot Study of Abacavir/Lamivudine and Raltegravir in Antiretroviral-Naïve HIV-1 Infected Patients: The SHIELD Trial. HIV Clinical Trials, 12, 228-233. http://dx.doi.org/10.1310/HCT1204-228

[11] Young, B., Fransen, S., Greenberg, K.S., et al. (2011) Transmission of Integrase Strand-Transfer Inhibitor Multidrug-Resistant HIV-1: Case Report and Response to Raltegravir-Containing Antiretroviral Therapy. Antiviral Therapy, 16, 253-256. http://dx.doi.org/10.3851/IMP1748

[12] Haskelberg, H., Hoy, J.F., Amin, J., et al. (2012) Changes in Bone Turnover and Bone Loss in HIV-Infected Patients Changing Treatment to Tenofovir-Emtricitabine or Abacavir-Lamivudine. PLoS One, 7, e38377. http://dx.doi.org/10.1371/journal.pone.0038377

[13] Rasmussen, T.A., Jensen, D., Tolstrup, M., et al. (2012) Comparison of Bone and Renal Effects in HIV-Infected Adults Switching to Abacavir or Tenofovir Based Therapy in a Randomized Trial. PLoS One, 7, e32445. http://dx.doi.org/10.1371/journal.pone.0032445

[14] Stellbrink, H.J., Orkin, C., Arribas, J.R., et al. (2010) Comparison of Changes in Bone Density and Turnover with Abacavir-Lamivudine versus Tenofovir-Emtricitabine in HIV-Infected Adults: 48-Week Results from the ASSERT Study. Clinical Infectious Diseases, 51, 963-972. http://dx.doi.org/10.1086/656417

[15] Reynes, J., Trinh, R., Pulido, F., et al. (2013) Lopinavir/Ritonavir Combined with Raltegravir or Tenofovir/Emtricita- 
bine in Antiretroviral-Naive Subjects: 96-Week Results of the Progress Study. AIDS Research and Human Retroviruses, 29, 256-265.

[16] Ofotokun, I., Sheth, A.N., Sanford, S.E., et al. (2012) A Switch in Therapy to a Reverse Transcriptase Inhibitor Sparing Combination of Lopinavir/Ritonavir and Raltegravir in Virologically Suppressed HIV-Infected Patients: A Pilot Randomized Trial to Assess Efficacy and Safety Profile: The KITE Study. AIDS Research and Human Retroviruses, 28, 1196-1206. http://dx.doi.org/10.1089/aid.2011.0336 